\title{
DUAL CHANNEL STREAM MONITOR
}

\author{
FINAL REPORT
}

to

Agricultural Research Service

Beltsville, Maryland

by

Earl E. Gray

and

S. S. Karaki

Colorado State University

Fort Collins, Colorado 
DUAL CHANNEL STREAM MONITOR

\author{
FINAL REPORT \\ to \\ Agricultural Research Service \\ Beltsville, Maryland \\ by \\ Earl E. Gray \\ and \\ S. S. Karaki
}

Colorado State University

Fort Collins, Colorado 


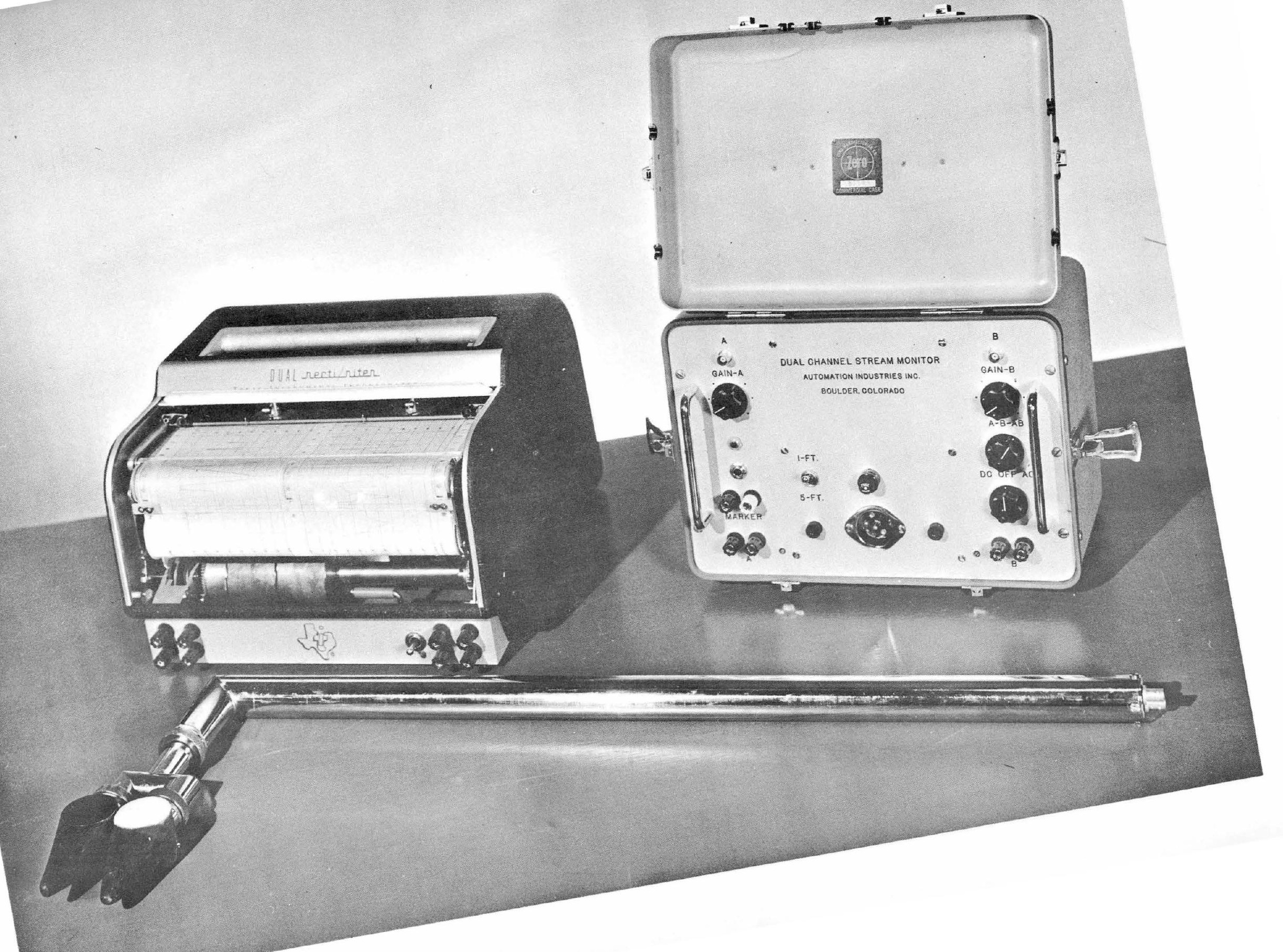




\section{ACKNOWLEDGMENT}

The development of the Dual Channel Stream Monitor was made possible through the sponsorship of the Agricultural Research Service, Beltsville, Maryland, and undertaken by Colorado State University with the cooperation of Automation Industries, Inc., of Boulder, Color ado. The instrument was tested and calibrated in the Hydraulics Laboratory of Colorado State University under both Static and dynamic conditions. The results of the tests and the technical description of the instrument are included in this report. 
Photo of Instrument (Dual Channel Stream Monitor)

ACKNOWLEDGMENTS .................... ii

LIST OF FIGURES .................. iv

LIST OF TABLES ................

INTRODUCTION $\ldots \ldots \ldots \ldots \ldots \ldots$

DESCRIPTION OF EQUIPMENT . . . . . . . . 2

CIRCUIT DESCRIPTION .............. 4

Power ...................... 4

Clock .................... 4

Pulser ...................... 4

Transducer .................... 5

Receiver ....................... 5

Computer ......................... 5

Recorder ................... 6

TESTING OF THE DUAL CHANNEL STREAM MONITOR • 7

Static Calibration Test .......... 7

Transducer Angle Tests . . . . . . . . . 9

Traverses over Stationary Sand Beds ...... 10

Static Water ............... 10

Moving Water .............. 11

Stationary Operation in a Movable Bed Flume ... 12

Transducer Traverse over Movable Sand Bed ... 12

Stationary Operation in a Movable Sand Bed

Channel with Standing Water Waves ...... 12

Battery Life Test .............. 13

Dual Channel Stream Monitor for Field Use . . . 14

Other Laboratory Tests . . . . . . . . . . . . 14

CONCLUSIONS $\ldots \ldots \ldots \ldots \ldots \ldots$ 


\section{LIST OF FIGURES}

Figure

Page

1. Definition Sketch .................. 9

2. Traverse Over Rigid Boundary Dunes,

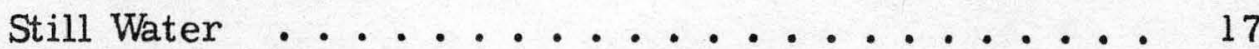

3. Traverses Over Rigid Boundary Dunes,

Moving Water ................ 18

4. Stationary Operation Over Moving Dunes ...... 19

5. Traverses Over Moving Dunes ........... 20

6. Operation Under Standing Wave Conditions ..... 21

7. Stationary Operation Over Moving Dunes ...... 22

8. Block Diagram ................ 23 


\section{LIST OF TABLES}

Table

Page

1. Static calibration tests. Stationary transducers in static water over stationary bed.

2. Results of transducer angle tests. ......... 


\section{INTRODUCTION}

An ultrasonic Dual Channel Stream Monitor capable of simultaneously measuring water surface and channel bed profiles under flow conditions has been developed at Colorado State University, Fort Collins, Colorado, under sponsorship of the Agricultural Research Service, Beltsville, Maryland. Automation Industries, Inc., Boulder, Colorado, provided technical assistance and assembled the instrument into a compact package. The instrument was developed basically for laboratory use, and is another step in the rapid technological progress in the use of ultrasonics. The instrument is completely transistorized, can operate with either standard 115 volt 60 cycle A. C. or battery power, and is considered to be adaptable for field use.

The instrument employs echo-ranging techniques similar to those used in Sonar. Sounding devices using echo-ranging techniques were first used as navigational aids for charting shoals, reefs, and depths. Then, during World War II, Sonar was used as a submarine detector and vast technical improvements were made. Following the war, sonic techniques were further improved by the Military in Anti-Submarine Warfare development and by civilian groups to improve navigational safety and commercial fishing efficiency. Other early use of ultrasonics was in determining flaws in castings and welds in industry. For the past two decades, the Corps of Engineers, Bureau of Reclamation and other Government Agencies have used modified Sonar equipment for determining sedimentation rates in reservoirs. The Colorado University Medical School and Automation Industries developed the Sonoscope in 1948 to map, nondestructively, pathological tissue growth in humans by ultrasonic methods. In 1954, Colorado State University, Animal Husbandry Section, obtained, through Automation Industries, a similar instrument for non-destructive determination of tissue growth in farm animals. At about the same time a similar instrument was developed in Germany. Later, in 1958, Cornell University developed a transistorized version of the same instrument and thus effected great portability of the instrument. 
Early in 1956 the Colorado State University and the U. S. Bureau of Public Roads jointly sponsored development of an instrument with Automation Industries, to measure scour depths of sand beds in Hydraulic Laboratory Research. Late in 1956, the U. S. Geological Survey and Automation Industries, collaborated in the development of a Sonic Depth Sounder to measure bed profiles in alluvial channels. This instrument was a single channel, vacuum tube unit which weighed in excess of $150 \mathrm{lbs}$ and required 500 watts of power to operate. In 1959 the Agricultural Research Service contracted with Colorado State University to develop an ultrasonic instrument to simultaneously record both water surface and stream bed configuration in laboratory flumes with sand beds. This resulted in the transistorized Dual Channel Stream Monitor discussed in detail in this report.

In echo ranging, a short burst, or pulse, of sound energy is introduced into the water through a transducer. This energy travels outward from the transducer until it strikes a surface formed by a distinct change in density of the medium, such as an air-water interface or the boundary between water and stream bed. A portion of the energy striking such a surface will be reflected and will return to the transducer. Sound travels at a relatively constant velocity in water so that the time lapse between outgoing pulse and returning 'echo' is directly proportional to distance from the transducer face to the reflecting surface. The echo-ranging device measures this time lapse and converts it to distance.

\section{DESCRIPTION OF EAUIPMENT}

The instrument described in this report employs two transducers, one directed vertically upward to interrogate the water surface and the other pointed vertically downward to interrogate the stream bed. The transducers employed are piezzo-electric crystals having a natural frequency of one megacycle. When pulsed electrically these crystals will vibrate mechanically at their natural frequency and, in the reverse sense, when mechanically agitated 
at their natural frequency they will produce an electrical signal. The transducers are pulsed alternately at a rate determined by the range selector switch.

The instrument has two ranges of operation, zero to one foot and zero to five feet. The difference in the two ranges is the repetition rate of the interrogating pulse. On the zero to one foot scale it is possible to operate in flow depths to two feet, one foot or less to the water surface and one foot or less to the stream bed. On the five foot scale it is possible to operate in depths to 10 feet.

The instrument is encased in a 'splash-proof' metallic container 9 inches high, 13 inches wide and 9 inches deep. Total weight of the sonic device is approximately 15 pounds including battery-pack or about 5 pounds without the battery-pack. Power requirements is 15 watts, 115 volts, 60 cycle or the battery pack noted above.

Readout for the equipment is accomplished through a dual-channel, pen type, strip-chart recorder having 1500 ohms input impedance and full scale deflection of one milliampere. The recorder used during testing and recommended for use with the device is the Texas Instrument Company's "Dual Recti-Riter" Rectilinear Recording Milliameter. This recorder weighs approximately 50 pounds and is fitted in a splash-proof case that is 14 inches high, 24 inches wide and 24 inches deep. Other recorders having the same full scale sensitivity and input impedance are available and could be used with the instrument.

Cables to connect the instrument to the transducers are $40 \mathrm{ft}$ lengths of RG-62U, co-axial transmission line. The cables are employed as part of a tuned circuit in the equipment so that use of different lengths of cables or of different types of cable would require re-tuning of the instrument. 


\section{CIRCUIT DESCRIPTION}

The circuitry of the basic instrument can be sub-divided into six major sections or components as shown in Figure 8, "Block Diagram". The components are power supply, clock, pulser, transducer, receiver, and computer. The recorder, circuit description of which is not included here, is an added package to the total instrument.

Power - The power supply has three sections providing three different D. C. output potentials. Section one is an unregulated, low current, positive 180 volt supply. Section two is a regulated $22-1 / 2$ volt positive supply and section three is a regulated $22-1 / 2$ volt negative supply.

Clock - The clock consists of a unijunction transistor relaxation oscillator and a bistable multivibrator. The relaxation oscillator produces negative spikes to trigger the bistable multivibrator which gives two, out of phase, square wave outputs. The frequency of the relaxation oscillator is determined by the position of the range selector switch, $1 \mathrm{kc}$ for the one foot range and $200 \mathrm{cps}$ for the $5 \mathrm{ft}$ range. The square wave output frequency is half the frequency of the relaxation oscillator.

Pulser - The square wave output of the clock is differentiated in the pulser. The spikes thus obtained are used as triggers to activate the silicon controlled switch in the pulser. This silicon controlled switch controls the charge and discharge paths for a capacitor. When the switch is "open" the capacitor charges to a voltage between 0 and 180 volts as controlled by the sensitivity control. When the switch is closed by the spike of voltage from the differentiated clock signal, the capacitor discharges through a parallel resonant circuit consisting of a resistor, a coil, and the capacitance of the coaxial transmission line with the transducer. This discharge produces a 
ringing in the tank circuit which activates the transducer. The magnitude of the ringing is controlled by the magnitude of the charge on the capacitor which is in turn controlled by the setting of the sensitivity control.

Transducer - The transducer is a Barium Titanate crystal cut to oscillate at a one megacycle rate and mounted to produce unidirectional mechanical vibrations with a very narrow beam width. When the crystal is pulsed with a high voltage it will vibrate mechanically for a short period of time at its natural frequency, and will produce sound waves of that frequency in the surrounding medium. The crystal is mounted such that vibrations in all but one direction are quickly absorbed. If the outgoing sound energy strikes a barrier produced by a difference in density, some of the energy will be reflected and return to the transducer. When the transducer crystal is mechanically agitated at its natural frequency it will produce a small electric signal at that frequency. This signal, referred to as an echo, is returned to the instrument via the same coaxial cable that fed the transmitter pulse from the pulser to the transducer.

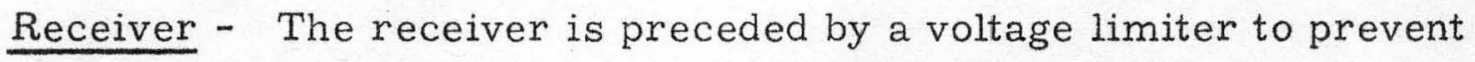
the transmitter pulse from over-driving the amplifiers. Following the diode limiter there are two stages of amplification which feed through an emitter follower, which prevents loading of the amplifiers, to the detector. The detector is a standard peak detector employing an R.C. time constant, too slow to follow the R.F. signal, but fast enough to follow the signal envelope. The output of the detector is fed through another emitter follower, to prevent loading of the detector, to a video amplifier which provides the signal to the computer.

Computer - The computer consists of a Bistable multivibrator and an emitter follower having zener diode output regulation. The Bistable 
multivibrator has two trigger inputs, a pulse from the clock and the receiver output. The receiver output consists of two, or more, pulses; the transmitter pulse and echo or echoes. The transmitter pulse and the clock pulse occur almost simultaneously such that only the first to occur, the clock pulse, serves to switch the multivibrator on. The echo, which comes a short time later, switches the multivibrator off. The output is a rectangular wave having an "on "period equal to the time lapse between clock pulse and echo return, and a period equal to the repetition rate of the transmitter pulses. This rectangular wave is fed through the emitter follower, where peak output voltage is regulated to 6 volts, to the recorder.

Recorder - The recorder is an average reading device which integrates the rectangular wave and records accordingly. Since the magnitude of the rectangular wave is regulated by the zener diode, the average value of the output is directly proportional to the "on" time and hence the time lapse between clock pulse and echo return.

The total equipment for the Dual Channel Stream Monitor consists of one clock, two pulsers, two transducers, two receivers and two computers. The two channels operate alternately, channel ' $A$ ' triggering on the positive going swing of the clock output and channel ' $B$ 'triggering on the negative going swing of the clock output.

In describing the receiver output, reference is made to "one or more" echoes. Repeated echoes may occur when sound energy is reflected from the primary surface, again from the transducer face or another surface, and once again from the primary surface. These "secondary" echoes may introduce erroneous readings if the period of the "secondary" echo is such that it occurs after the succeeding transmitter pulse but before the next primary echo. Secondary echoes are usually unstable in magnitude and the experienced operator will recognize them quite readily. Adjustment of the sensitivity control will usually eliminate these echoes. 
TESTING OF THE DUAL CHANNEL STREAM MONITOR

The Dual Channel Stream Monitor was thoroughly tested in the hydraulics laboratory of Colorado State University. Tests conducted with the instrument included: (1) static calibrations of the monitor over stationary sand beds of both water surface and stream bed channels and with both one and five foot range scales; (2) transducer angle tests to determine the maximum allowable angle between transducer face and the reflecting surface before loss of signal occurred; (3) traverses over stationary sand beds with still water; (4) traverses over stationary sand beds with flowing water; (5) stationary operation of the monitor in an alluvial flume involving moving sand beds of various sand sizes and flow velocities; (6) traverse in an alluvial flume with moving sand beds of various sizes and flow velocities; (7) operation under shallow flow and standing wave conditions; (8) Battery life tests and (9) operation with transducers mounted in a 100-1b lead weight.

\section{Static Calibration Test}

Static calibration tests of the Dual Channel Stream Monitor were performed over sand beds and with screen covered metal surfaces. Screen was used to attenuate the sound waves reflecting from a flat metal surface. Measurements of the distances from the transducer face to the reflecting surfaces were made with a point gage and in cases of large depths with steel scale. The actual distances measured were recorded on the recorder chart along with the distances recorded by the monitor. A tabulation of the results of the tests is shown in Table 1 .

A reproduction of the chart used in the recorder is shown in Fig. 2. With the 1 -ft monitor scale, the chart can be read accurately to $.02 \mathrm{ft}$ and estimated to the nearest $0.01 \mathrm{ft}$. On the 5 - $\mathrm{ft}$ scale the chart can be read accurately to $0.10 \mathrm{ft}$ and estimated to the nearest $0.05 \mathrm{ft}$. The recorder accuracy is specified by the manufacturer as \pm 2 per cent of full scale reading. 
TABLE 1 .

STATIC CALIBRATION TESTS. STATIONARY

TRANSDUCERS IN STATIC WATER OVER STATIONARY BED.

\begin{tabular}{|c|c|c|c|c|c|}
\hline \multirow{3}{*}{$\begin{array}{l}\text { Actual } \\
\text { Depth }\end{array}$} & \multicolumn{4}{|c|}{ Monitored Depth } & \multirow{3}{*}{$\begin{array}{l}\text { Reflecting } \\
\text { Surface }\end{array}$} \\
\hline & \multicolumn{2}{|c|}{$1 \mathrm{ft}$ scale } & \multicolumn{2}{|c|}{$5 \mathrm{ft}$ scale } & \\
\hline & Channel A & Channel B & Channel A & Channel B & \\
\hline $0.17 \mathrm{ft}$. & 0.17 & $0.17+$ & 0.21 & 0.20 & sand \\
\hline 0.32 & $0.31+$ & 0.32 & 0.31 & 0.33 & " \\
\hline 0.50 & 0.48 & $0.49+$ & $0.49+$ & 0.50 & " \\
\hline 0.66 & 0.66 & $0.65+$ & 0.63 & 0.65 & $" 1$ \\
\hline 0.83 & $0.82+$ & $0.82+$ & 0.83 & 0.82 & $" 1$ \\
\hline 1.0 & $0.99+$ & 1.00 & $1.00^{-}$ & 1.00 & " \\
\hline 1.0 & $\cdots-$ & $\ldots$ & 1.00 & 0.98 & Screen \\
\hline 1.5 & $\cdots$ & $\cdots$ & 1.49 & 1.48 & 11 \\
\hline 2.0 & $\cdots-$ & $\cdots-$ & 1.99 & 2.00 & $"$ \\
\hline 2.5 & $\ldots$ & $\cdots$ & 2.50 & 2.50 & " \\
\hline 3.0 & $\cdots$ & $\ldots$ & $3.00+$ & 3.05 & " \\
\hline 3.5 & $\cdots-$ & $\ldots-$ & $3.55^{-}$ & 3.55 & $" 1$ \\
\hline 4.0 & $\cdots-$ & $\cdots-$ & 4.05 & 4.05 & " \\
\hline 4.5 & $\ldots-$ & $\ldots$ & 4.55 & $4.5+$ & $"$ \\
\hline 5.0 & $\ldots$ & -..- & 4.99 & 4.95 & " \\
\hline
\end{tabular}


The maximum deviation between actual depth and Monitor reading in Table 1 was $0.05 \mathrm{ft}$ on the five-foot scale and $0.02 \mathrm{ft}$ on the one-foot scale.

\section{Transducer Angle Tests}

Transducer angle tests on the Dual Channel Stream Monitor were conducted to determine the maximum allowable angle between the transducer face and the reflecting surface. The tests were also conducted to determine whether the instrument reading was the distance along the hypotenuce of the triangle formed by angle of inclination or the shortest distance between transducer and reflecting surface. This test was conducted with a stationary horizontal sand bed and in static water. A sketch of the transducer arrangement is shown in Fig. 1 and data obtained are given in Table 2.

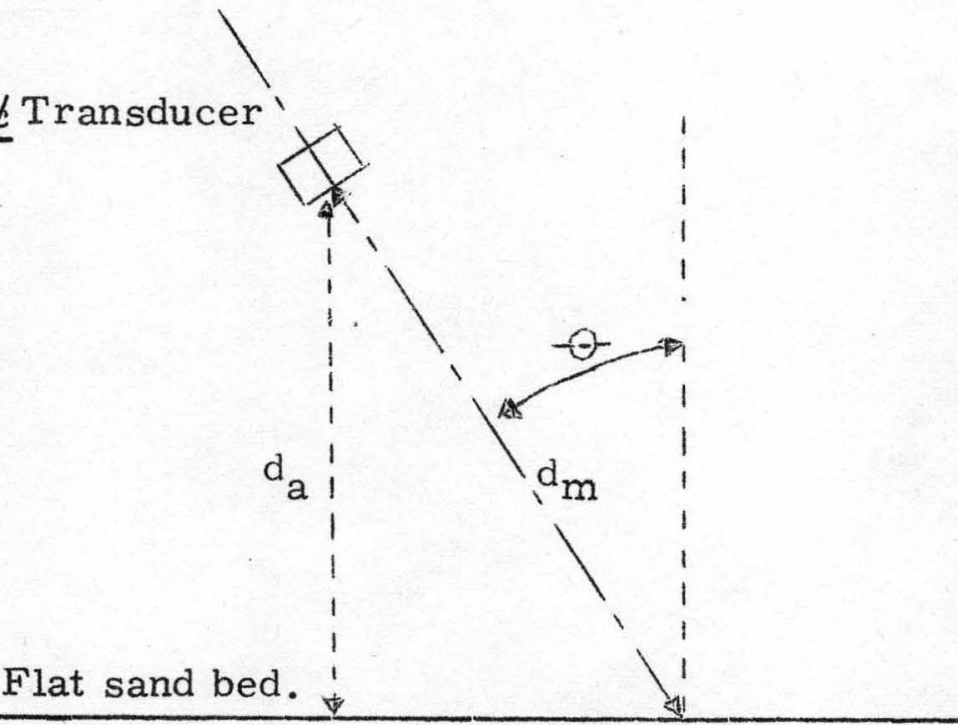

$\begin{aligned} \theta= & \text { Angle of incli- } \\ & \text { nation. } \\ d_{a}= & \text { Shortest distance } \\ & \text { from } \notin \text { of } \\ & \text { transducer to } \\ & \text { sand bed } \\ d_{m}= & \text { Distance along } \\ & \underline{E} \text { of trans- } \\ & \text { ducer to sand bed. }\end{aligned}$

Fig. 1 Definition Sketch. 
TABLE 2.

RESULTS OF TRANSDUCER ANGLE TESTS.

\begin{tabular}{|c|c|c|c|}
\hline$\theta$ & $\mathrm{d}_{\mathrm{a}}$ & $\mathrm{d}_{\mathrm{m}}$ & Monitor reading \\
\hline $5^{0}$ & 0.69 & 0.69 & 0.69 \\
$10.50^{\circ}$ & 0.71 & 0.72 & 0.72 \\
$15.33^{\circ}$ & 0.71 & 0.74 & 0.74 \\
$20^{\circ}$ & 0.71 & 0.76 & 0.76 \\
$24.67^{\circ}$ & 0.72 & 0.80 & 0.80 \\
$32.33^{\circ}$ & 0.70 & 0.82 & 0.82 \\
\hline
\end{tabular}

Maximum allowable angle of the transducer was approximately 32 degrees. Beyond this angle the ultrasonic echoes did not return to the transducer. Table 2 also shows that the instrument measures the distance from transducer face to reflecting surface along the transducer center-line; virtually no correction is necessary to monitored distance for transducer angles less than 10 degrees.

\section{Traverses over Stationary Sand Beds}

\section{$\underline{\text { Static Water }}$}

Stationary sand dunes were constructed in a 2-ft flume with sand $0.3 \mathrm{~mm}$ in diameter bonded together with a lean mixture of portland cement ( 1 part in 15). The transducer was traversed over the dunes and actual measurements of the dune profile and the distance from transducer face to dune surface was made with a point gage. The points of measurement were marked on the side of the 
flume, and the traverses were matched correspondingly with event markers on the chart.

After completion of the tests the point gage measurements were repeated and found to be unchanged. The measured depths were then plotted on the recorder chart, superimposed on the monitor record. A typical result is shown in Fig. 2.

A significant feature noted in Fig. 2 is the time lag between the recorded distance and the actual event. This time lag which was also evident in other tests was primarily due to the inherent lag of the recorder. The recorder has a maximum frequency response of about one cycle per second and performs as an integrating recorder. The recorder chart speed during the traverse was 3 inches per minute; traverse velocity was approximately 18 inches per minute. Another reason for the apparent time lag is undoubtedly due to slight tilting of the transducer to a trailing position because of the flexibility of the search tube assembly. Considering the time lag, the maximum deviation between monitor reading and point gage plot was about $0.02 \mathrm{ft}$.

\section{Moving Water}

Accuracy tests for the instrument were also conducted under dynamic conditions in the same flume and over the same rigid dunes as the static water tests. Actual dune profiles before and after tests were made and only slight differences were noted. A typical result of the tests is shown in Fig. 3. The time lag effect was apparent also in these tests and the amount of lag was approximately the same as the static tests. Accuracy after correcting for time lag was within $0.02 \mathrm{ft}$. Flow velocity during these series of tests was approximately $6 \mathrm{ft} / \mathrm{sec}$ with considerable surface turbulence developed immediately downstream from the dune. An increase in gain was necessary under dynamic conditions over that required in static water. 
Stationary Operation in a Movable Bed Flume

In this series of tests the Dual Channel Stream Monitor was subjected to operational tests in a movable bed, 2-ft tilting flume. Average sand size of the alluvial bed was $0.3 \mathrm{~mm}$ in diameter and flow velocity was varied from 0.75 to 4 feet per second. The instrument was tested in the ripple and dune regimes. Figure 4 is a reproduction of a three-hour test performed on July 14,1960 , with dune formations on the bed. The test results indicated that the ultrasonic echoes respond well under dynamic conditions in an alluvial flume.

Transducer Traverse over Movable Sand Bed

Figure 5 is a reproduction of two traverses in a downstream direction over an alluvial bed of the same sand sizes used in the stationary tests. The two traverses were made at periods five minutes apart. Event markers were made on the chart at ten foot intervals on the flume during the traverse. Chart speed was three inches per minute, flow velocity was approximately four feet per second. The same dune formations can be easily traced on the recorder chart. If the chart speed is known and distance marks are made on the recording chart, the total distance traversed and time of traverse is easily determined. For some research applications, this type of information may be desirable. From the chart record, the height, shape and spacing of the dunes are easily determined. For stationary transducer positions, the dune movement in a downstream direction can be easily traced, and its travel speed determined.

Stationary Operation in a Movable Sand Bed Channel with Standing Water Waves

Figure 6 is a reproduction of a portion of the tests conducted with standing water waves in a sand bed flume. The test was conducted in an eightfoot wide tilting flume. Flow velocity was approximately 7 feet per second, and average depth was 0.5 feet. The average sand size of the bed was $1 \mathrm{~mm}$ 
in diameter. Chart speed was 3 inches per minute. Reproduction of standing waves on the surface was accomplished with excellent results, although during breaking waves, there was an appreciable amount of air entrainment disturbance. Because of the large sand size, and large concentration of suspended sediment adjacent to the bed, the monitored signal occasionally recorded a false depth to bed surface. This problem will be minimized in applications in the Agricultural Research Service Hydraulics Laboratory in Oxford, Mississippi, however, because of the much smaller sand sizes used, but if the concentration of suspended sediment increases, the ultrasonic echoes will be reflected from some point within the suspended layer.

If the concentration increases to such a degree, it remains as an academic question as to the definition of the "true" bed surface.

\section{Battery Life Test}

Battery life tests were conducted for the Dual Channel Stream Monitor. Normally, it is expected that AC power will be used in the laboratory; however, for field use and specialized laboratory use, it may be necessary to utilize battery power. A new battery pack, consisting of two 90-volt, Eveready N-60, dry cells and one 45-volt, center tapped, Burgess 5308, dry cell was installed immediately before the test was started. A 15 minute warm-up period was allowed for the equipment before final adjustment of the gain control was made. After fourteen hours of continuous operation it was necessary to readjust the gain controls slightly as secondary echoes began to appear. After this readjustment of the gain control normal operation continued for another fifteen hours before further adjustment was necessary. Beyond the twenty-ninth hour of continuous operation, constant adjustment of the gain controls was found to be necessary to maintain satisfactory operating conditions. At approximately the end of thirty-three hours, the power provided by the battery pack was considered insufficient to maintain satisfactory reliability in operation. 


\section{Dual Channel Stream Monitor for Field Use}

The possibility of utilizing the Dual Channel Stream Monitor in the field by mounting the transducers in a 100-1b lead current meter weight was investigated in the laboratory. The transducers were mounted in the lead weight with one transducer placed flush with the top of the weight and the other flush with the bottom. The transducer cables were imbedded in the weight and were made watertight. It is expected that the lead weight will be manipulated from a cableway in the same manner as the current meters are presently operated.

The lead weight assembly was tested in the laboratory and satisfactory results of depth recordings were obtained. One of the problems expected for field use of this assembly is associated with trash and debris. It is important in recording water-surface profiles that trash not be allowed to collect on the cable. The cable must not interfere with the ultrasonic signal, and a suggested modification from the standard suspension system is to provide a dual cable suspension for a distance of five feet above the lead weight and hence to a single cable. An anchor cable attached to the tail of the lead weight may be required for stabilization. A technique of field operation will surely be developed as experience is gained with the total assembly.

\section{Other Laboratory Tests}

Several miscellaneous tests were made in the laboratory with the search tube assembly of the Dual Channel Stream Monitor. A series of tests to determine the effect of flow velocity on monitored accuracy was made in a supercritical flume. With a fixed position of the transducer, the velocity of flow was varied from 1 to 12 feet per second. No noticeable deviation in depth reading was noted. Tests were also made to devermine the minimum flow depth in which the transducer could be used. If both water surface and bed profile data are required, the minimum depth is $0.44 \mathrm{ft}$. At this depth however, and 
velocities greater than 1 foot per second, there will be a local scour effect at the transducer, which thus gives erroneous impressions of bed profile. For staisfactory operation, the transducer face should be approximately 0.25 to $0.3 \mathrm{ft}$ from the reflecting surface:

\section{CONCLUSIONS}

The Dual Channel Stream Monitor requires a warm-up stabalization period of approximately thirty minutes. When operated with the Texas Instrument Dual Recti-Riter for data readout, the total instrument complex has an accuracy of $\pm 0.05 \mathrm{ft}$ on the five-foot scale and $\pm 0.02 \mathrm{ft}$ on the onefoot scale. The accuracy is limited by the accuracy of the recorder. It is possible to improve the accuracy if needed, by use of a more sensitive and therefore more expensive recorder.

The instrument operates satisfactorily with transducers in a stationary mounted position and in traverse over both rigid and movable sand beds. A finite time lag is apparent where rapid change in depth occurs but this does not affect the accuracy of the instrument. In most hydraulic research the relative sizes and shapes of the sand dune formations is more important than the position of the dune with respect to laboratory flume. Therefore, the time lag noted above does not detract from the usefulness of this instrument.

The depth measured by the instrument to a reflecting surface is the distance from transducer face along the transducer centerline. The maximum angle of inclination with respect to the reflecting surface is approximately 32 degrees. The ultrasonic beam width emitted from the transducer is very small so that essentially point readings of bed and water surfaces are recorded. Extreme angles of smooth surfaces will cause loss of echo and are registered as an erratic reading on the recorder. 
The wave length of sound of one megacycle frequency in water is approximately sixty thousandths of an inch or $1.5 \mathrm{~mm}$. The sound waves will be reflected from surfaces approximately one-half the wave length in size or larger, so that suspended particles larger than thirty thousandths of an inch will tend to produce spurious echoes. Large concentrations of suspended particles or air bubbles may produce a reflection of the sound waves and cause erroneous readings of depth to bed or water surface.

Flow velocity of water has little effect on instrument operation though extremely high velocities will require some increase of gain. Surface turbulence associated with high velocity produces little difficulty. The Dual RectiRiter recorder is an integrating instrument having a frequency response of one cycle per second so that rapid surface variations will be averaged out and will not be reproduced in detail on the chart. In normal hydraulic research, the integrating effect is desirable. If it is deemed necessary however, to follow these rapid fluctuations, a high quality voltage calibrated oscilloscope with strip filus ramora can be used to measure depth.

The Dual Channel Stream Monitor normally operates on a 115-volt, 60 cycle, alternating current and draws about fifteen watts of power. The instrument complex includes a battery pack from which it can be operated if $\mathrm{AC}$ power is not available. Battery life under normal conditions and continuous use is approximately thirty hours with some adjustment of gain controls necessary during this period. 


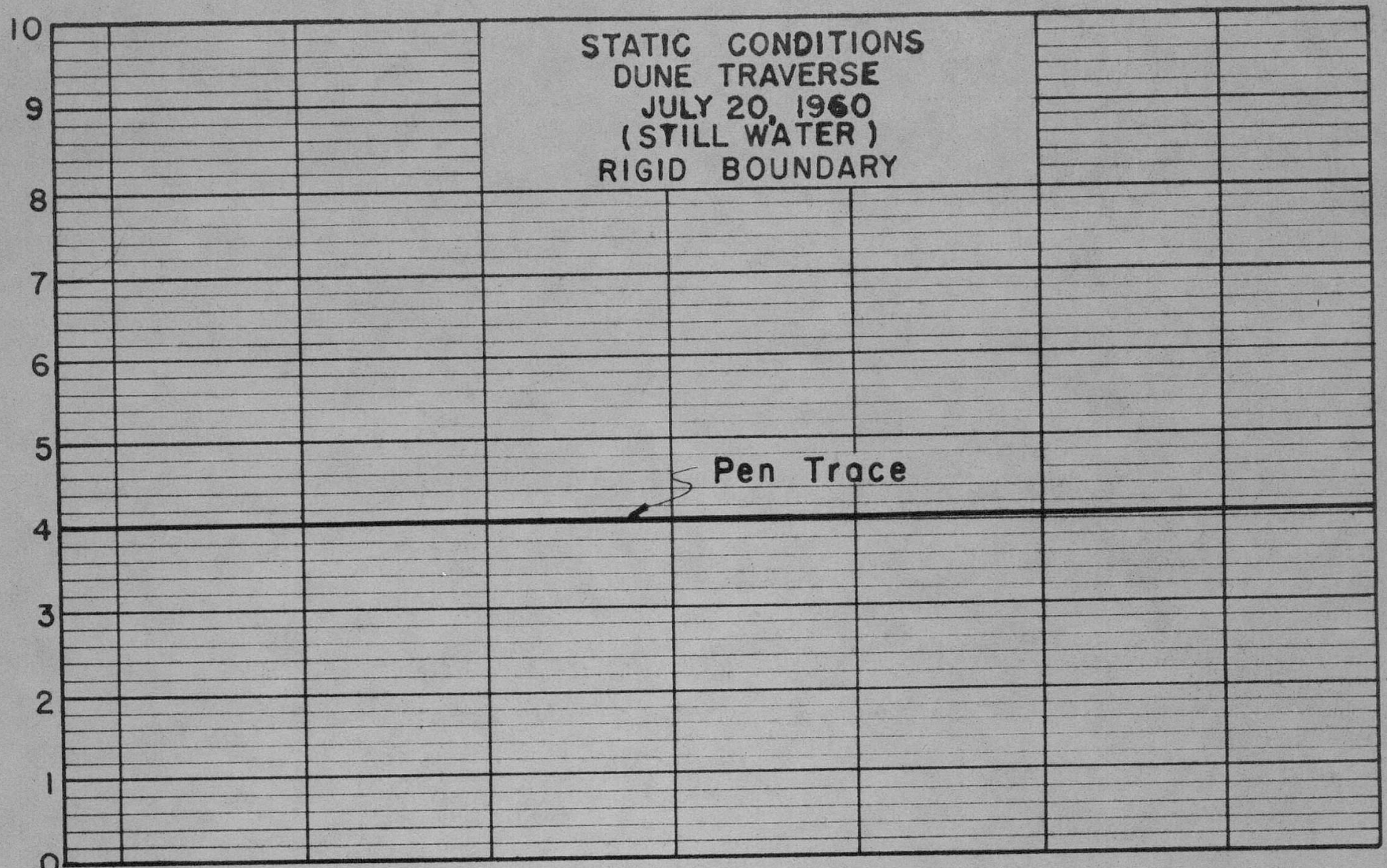

Dual Channel Stream Monitor Record of traverse over rigid boundary dunes, point gage measurements superimposed in dotted 1ines. Standing water, chart speed three inches per minute, event markers spaced at two inch intervals.

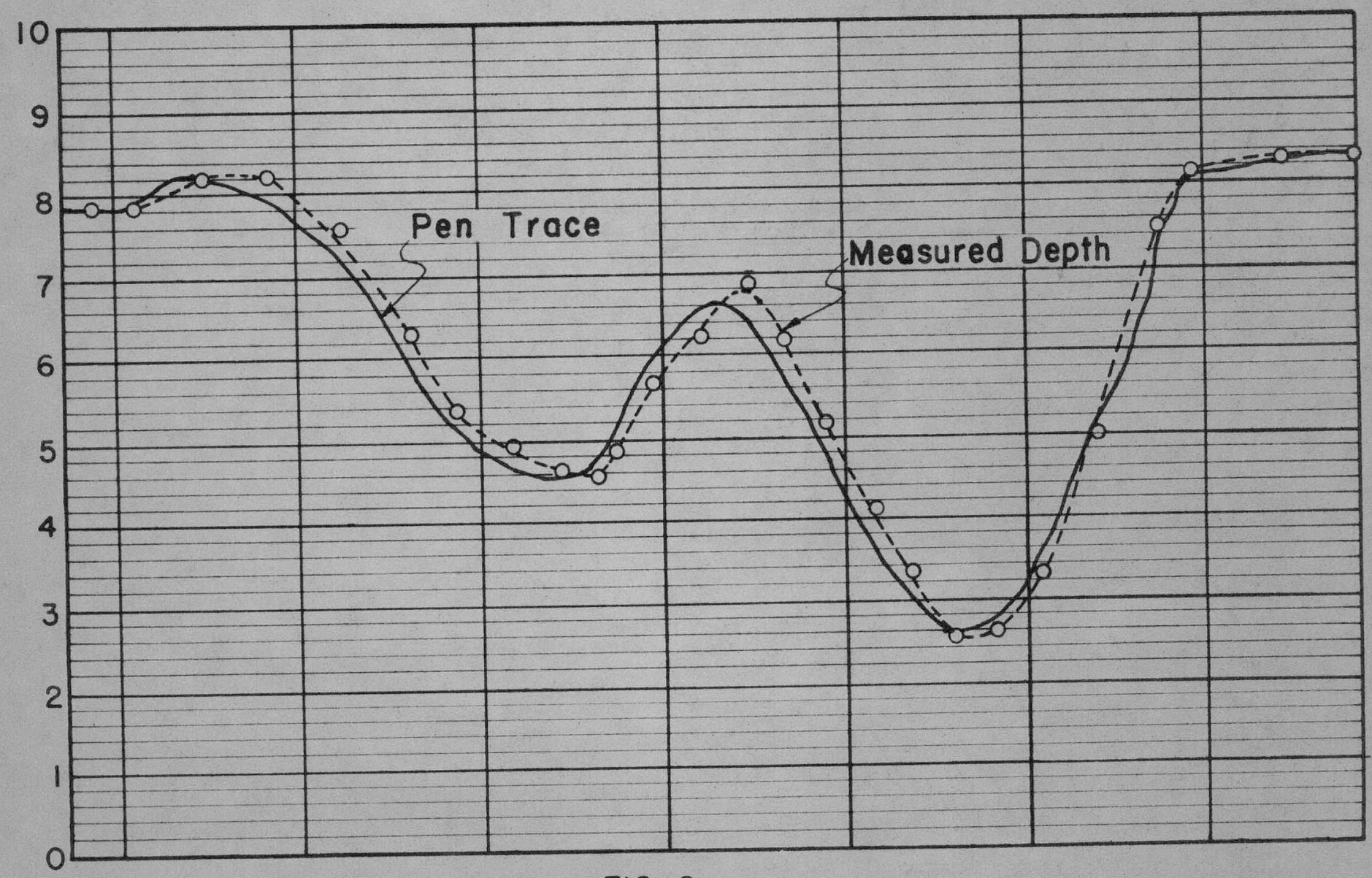

FIG. 2 


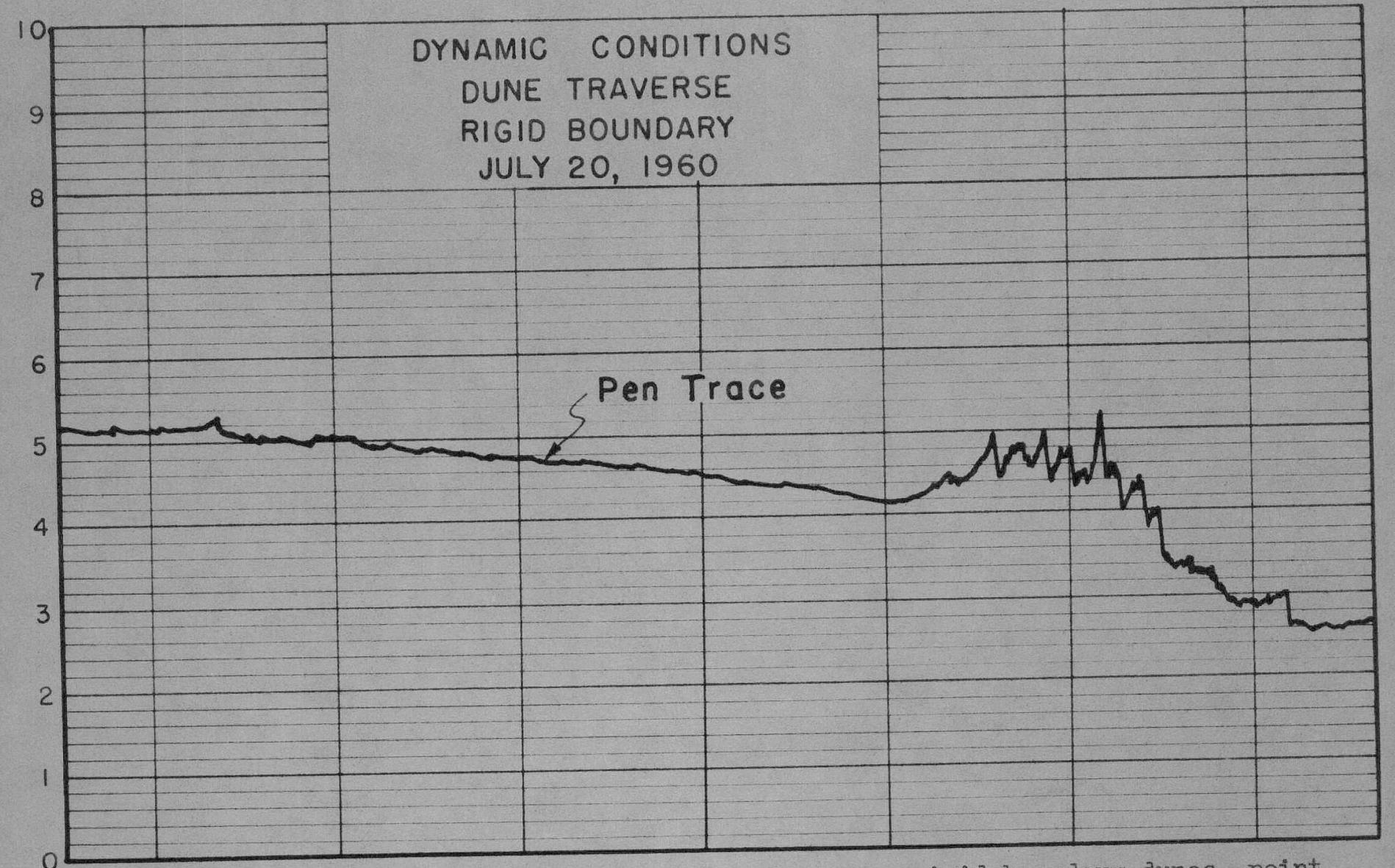

Dual Channel Stream Monitor Record of traverse over rigid boundary dunes, point gage measurements superimposed in dotted lines. Flow velocity over dunes approximately six ft per second, chart speed three inches per minute, event markers

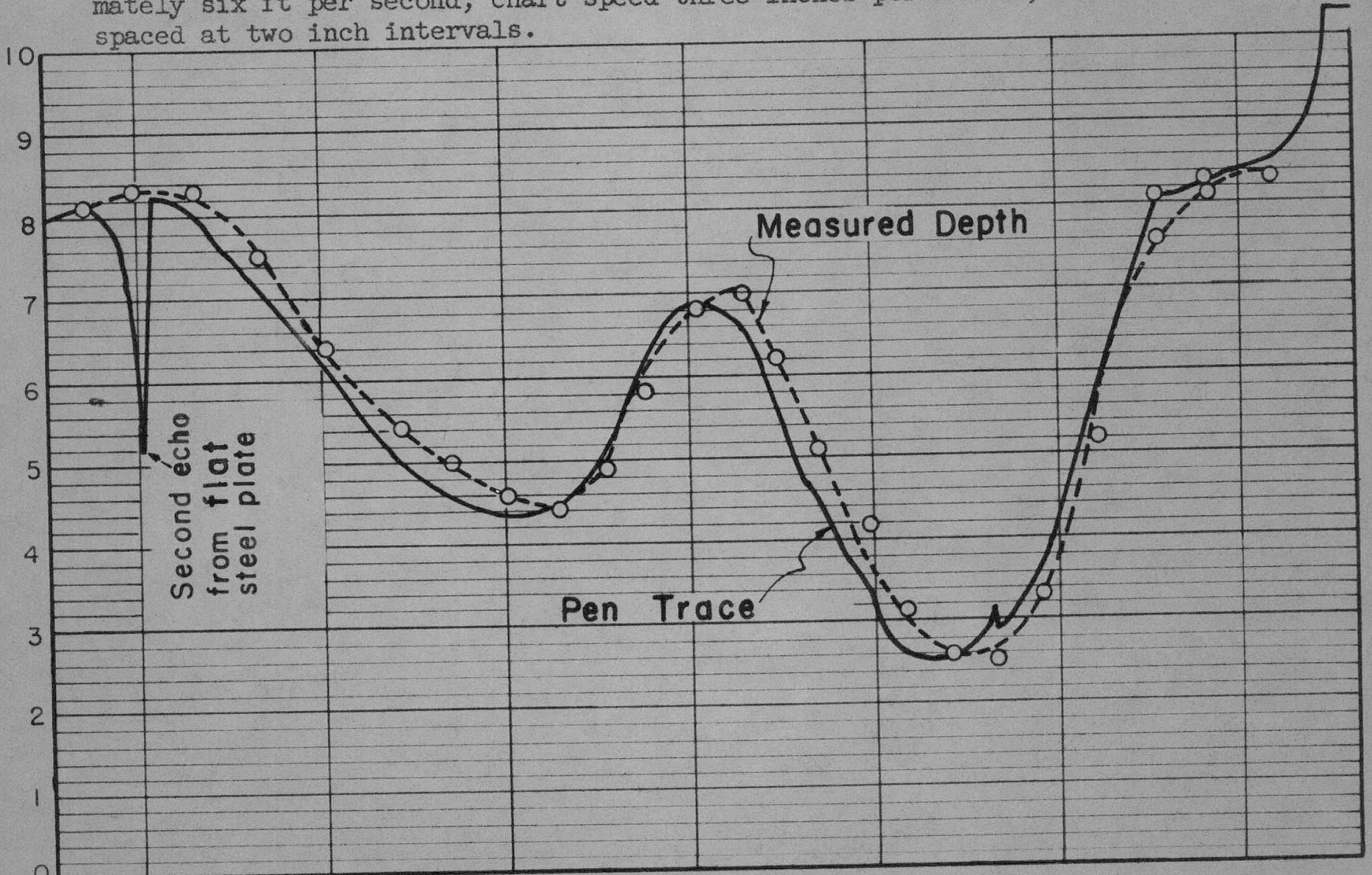

FIG. 3 


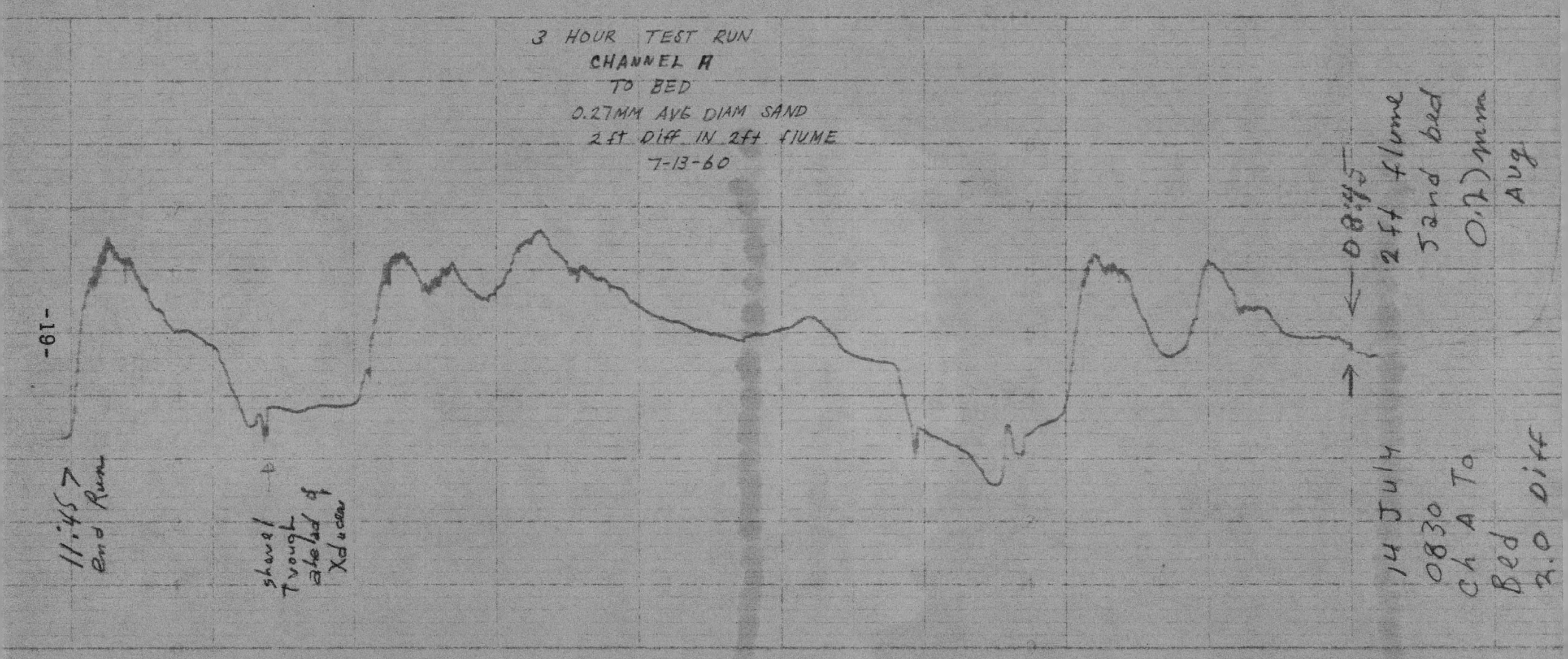

F1g. 4 Dual Channel Stream Monitor Record of three hour test rum in two foot tilting flume over moving dunes. Transducer rigidly mounted with channel B to Bed, surface record not taken. Average flow velocity four feet per second, chart speed three inches per hour, average particle size 0.27 man. 


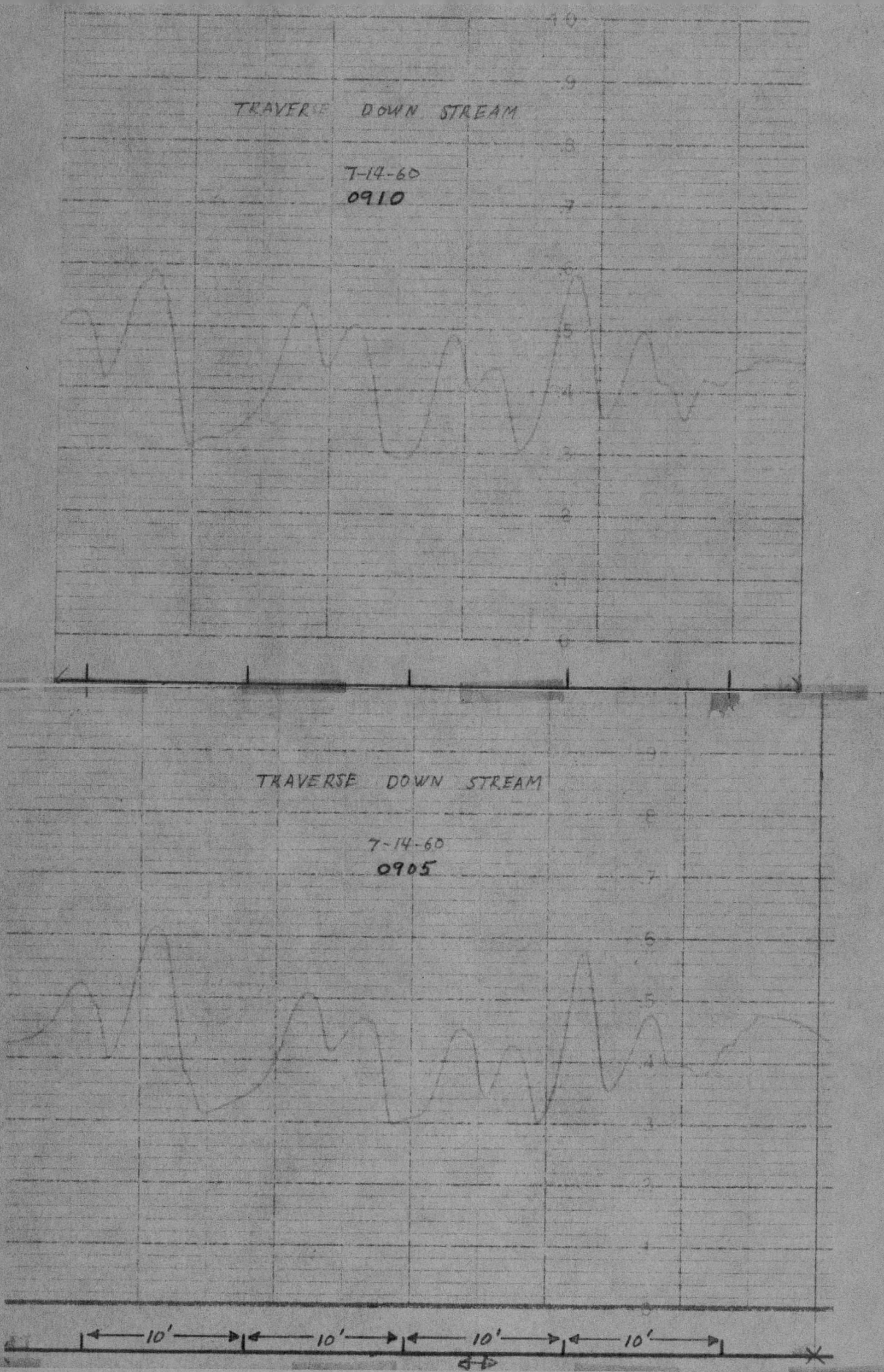

Fig. 5 Dual Channel Stream Monitor Records taken during transverse over noving dunes in two toot tilting flume. Flow velocity approximately four feet per second, chart speed three inches per minute, average particle size $0.27 \mathrm{~mm}$, ten foot spacing on event markers. Upper chart record made five minutes after lower. 

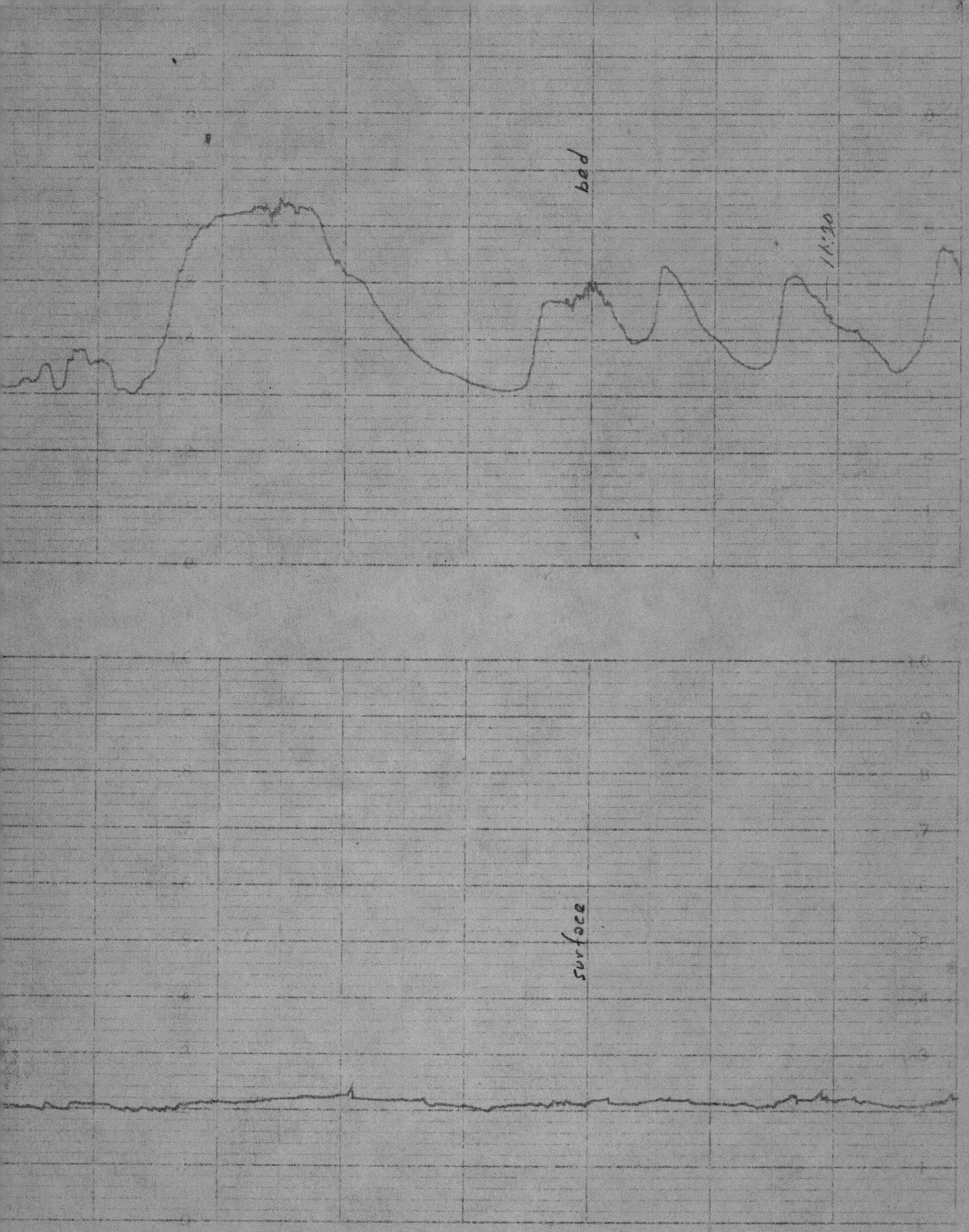

Fig: 7 Dual Channel Stream Monitor Record of moving dunes in two foot, tiltins flume. Transducers rigidly mounted with channel A to Bed, channel B to water surface. Flow velocity approximately four feet per second, chart speed 3 inches per hour, average particle size $0.27 \mathrm{~mm}$. 


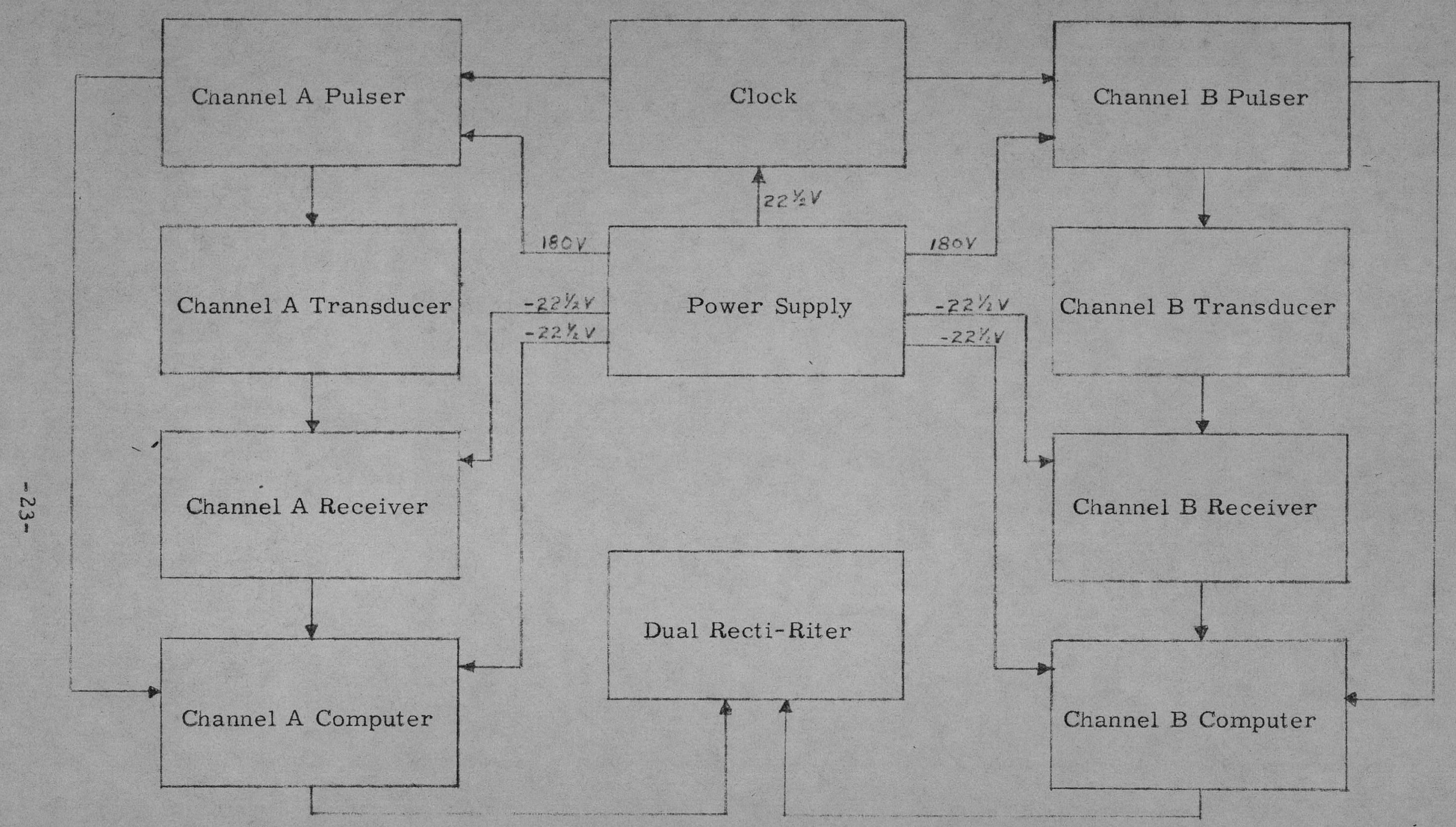

Fig. 8 Dual Channel Stream Monitor Block Diagram 